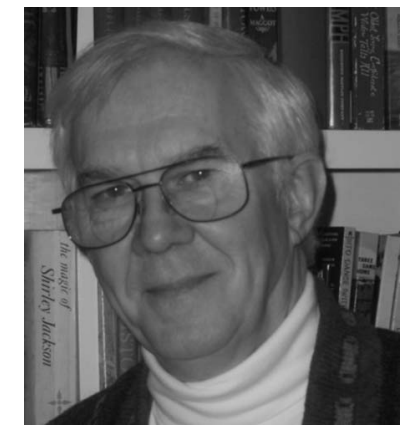

\section{5 in Review}

The February editorial is used to report to SPIE members and readers of this journal on its status at the beginning of 2006. In the year just past, the editors and staff of Optical Engineering completed the transition from a softwarebased manuscript handling system to a browser-based system, Peer X-Press, hosted by the American Institute of Physics. Although there have been some hiccups and odd occurrences, on the whole the system has performed admirably. Because all transactions, from manuscript submission to peer reviewing and decisions, are now available from most web browsers, we have greater flexibility as to where and when we can work. During two trips this past year, I assigned papers to the Associate Editors while in Sorrento (in an Irish pub/Internet cafe!) and in Warsaw. Information on Peer X-Press can be found at http:// www.peerx-press.org/ and submissions can be made at http://oe.peerx-press.org/. Click the Author information tab for additional help.

In the past, SPIE members had a choice of receiving their journal in either print or online form. From now on this journal will be delivered electronically to members. Those who wish to receive a print copy must pay an additional cost. I realize that for some readers the substitution of an electronic version for a paper copy may not seem as convenient right now. But I think you will find, over time, that the ease of access and search capability across many issues will prove to be more useful than when you scanned these pages and then stored them on the bookshelf.
Also, during the past year, we began to publish papers online as soon as they have been copyedited, typeset into proofs, and corrected. Now, with electronic distribution you can read individual papers as soon as they are published, instead of waiting until all of the finished papers have been assembled to be printed and mailed as a complete issue. This should prove to be valuable to optical engineers doing research.

But enough of the future, let's dig up the past.

The number of papers published last year hit an alltime high. Over 500 papers were published, an increase of $22 \%$ over last year, although this is only $6 \%$ greater than the number of papers published in 2003. Table 1 lists the figures for the past five years. I have tried to discern a trend in our publication statistics over the years, but I have given up.

One striking difference between 2005 and previous years is the number of special section papers received and published (Table 2). At one time special sections were used to attract authors to publish in Optical Engineering. Then, for a time, papers from various countries and regions were featured in special sections. More recently, I contacted conference chairs and others to publish papers in their particular area. However, with the increase in submitted and accepted papers, I believe the emphasis should be directed to attracting significant papers that will serve the community. I have limited special section topics to those that have not been strongly represented in the journal or are "hot" topics that our readers should be aware of. In 2004 we published a large number of special topic papers, whereas last year we returned to the ratio of regular to special papers seen in 2003. Currently there are no special sections scheduled for 2006. However, proposals for specials are welcome and will be carefully considered.

The acceptance rate for manuscripts had declined substantially from $65 \%$ to under $50 \%$ during the past several years. But last year, the rate has returned to earlier values, as shown in Table 3. It is not easy to understand why the acceptance rate should increase so dramatically. The trend needs to be looked at in some detail to determine what has changed. With the new tracking ability provided by Peer X-Press, we may be able to understand some of the choices and changes that have occurred recently.

In contrast to the regular submissions, the acceptance rate for OE Letters remained about the same (Table 4). The number of letters accepted and declined increased. Those authors whose papers do meet the stricter criteria

Table 1 Major statistics for 2001-2005 and percentage changes from 2004.

\begin{tabular}{lcccccr}
\hline \hline & & & & & & \\
& 2001 & 2002 & 2003 & 2004 & 2005 & vs 2004 \\
\hline Number of journal pages & 2924 & 3360 & 3672 & 3164 & 3750 & $+18.5 \%$ \\
Number of technical pages & 2776 & 3210 & 3514 & 3023 & 3630 & $+20.1 \%$ \\
Number of papers published & 385 & 420 & 487 & 422 & 515 & $+22.0 \%$ \\
\hline \hline
\end{tabular}


Table 2 Regular vs. special section papers for 2003-2005 and percentage changes from 2004 (including OE Letters).

\begin{tabular}{lrrrrrr}
\hline \hline & 2002 & 2003 & 2004 & 2005 & 2005 ratio & $\begin{array}{r}2005 \\
\text { vs 2004 }\end{array}$ \\
\hline Regular papers published & 359 & 448 & 318 & 478 & $92.8 \%$ & $+50.3 \%$ \\
Special papers published & 61 & 39 & 104 & 37 & $7.2 \%$ & $-64.4 \%$ \\
Regular papers received & 643 & 781 & 912 & 875 & - & $-4.1 \%$ \\
Special papers received & 44 & 68 & 121 & 6 & - & $-95.0 \%$ \\
\hline \hline
\end{tabular}

Table 3 Outcomes of papers acted on in 2004 and 2005 (regular papers only; OE Letters not included).

\begin{tabular}{lcccccc}
\hline \hline & \multicolumn{2}{c}{2003} & \multicolumn{2}{c}{2004} & \multicolumn{2}{c}{2005} \\
\hline Accepted & 332 & $57.05 \%$ & 317 & $48.32 \%$ & 497 & $63.0 \%$ \\
Declined/Closed/Transferred & 248 & $42.61 \%$ & 331 & $50.46 \%$ & 287 & $36.4 \%$ \\
Withdrawn & 2 & $0.34 \%$ & 8 & $1.22 \%$ & 5 & $0.6 \%$ \\
Total & $\mathbf{5 8 2}$ & $\mathbf{1 0 0 \%}$ & $\mathbf{6 5 6}$ & $\mathbf{1 0 0 \%}$ & $\mathbf{7 8 9}$ & $\mathbf{1 0 0 \%}$ \\
\hline \hline
\end{tabular}

Table 4 OE Letters statistics for 2002 to 2005.

\begin{tabular}{lccccc}
\hline \hline & 2002 & 2003 & 2004 & 2005 & $\%$ \\
\hline Letters received & 80 & 124 & 118 & 131 & \\
Letters published & 27 & 36 & 39 & 50 & \\
Accepted & 26 & 39 & 41 & 50 & $38.5 \%$ \\
Declined & 48 & 77 & 69 & 80 & $61.5 \%$ \\
\hline \hline
\end{tabular}

Table 5 Number of papers published by region of first author in 2002 through 2005.

\begin{tabular}{|c|c|c|c|c|c|c|c|}
\hline Region & 2002 & 2003 & 2004 & 2005 & \multirow{3}{*}{\multicolumn{3}{|c|}{$\begin{array}{l}\text { Table } 6 \text { Activity of the editorial office in } 2005 \text { (regular papers only, } \\
\text { including OE Letters). }\end{array}$}} \\
\hline Africa & 1 & 0 & 2 & 5 & & & \\
\hline Asia & 154 & 211 & 172 & 212 & & & \\
\hline Australia & 8 & 8 & 3 & 5 & \multirow{2}{*}{\multicolumn{3}{|c|}{$\begin{array}{l}\% \text { change } \\
\text { vs } 2004\end{array}$}} \\
\hline Eastern Europe & 17 & 7 & 13 & 28 & & & \\
\hline Middle East & 14 & 15 & 14 & 10 & Reviewers selected & 5467 & $+61.27 \%$ \\
\hline North America & 139 & 161 & 142 & 152 & Reviews received & 1963 & $+36.89 \%$ \\
\hline South/Cent. America & 7 & 3 & 4 & 3 & Revised manuscripts received & 728 & $+65.46 \%$ \\
\hline Western Europe & 80 & 82 & 72 & 100 & Papers returned to authors for revision & 702 & $+24.25 \%$ \\
\hline
\end{tabular}


Table 7 Journal performance for reviews and publication time

\begin{tabular}{lccccc}
\hline \hline & 2001 & 2002 & 2003 & 2004 & 2005 \\
\hline Average time for review (weeks) & & & & & \\
Optical Engineering & 15.2 & 8.9 & 8.4 & 11.4 & 9.5 \\
Optical Engineering Letters & & 3.6 & 4.4 & 6.7 & 5.1 \\
Average time acceptance to publication (months) & & & & & \\
Optical Engineering & 5.6 & 6.4 & 5.8 & 5.6 & 5.8 \\
Optical Engineering Letters & & 3.0 & 3.2 & 3.4 & 2.3 \\
\hline \hline
\end{tabular}

for publishing an $O E$ Letter benefit not only from rapid publication (see below), but also from the fact that letters are now being published as Open Access documents, so that anyone visiting the SPIE Digital Library can download them.

To give you some idea where our papers come from, I have included the data for the past four years in Table 5, which gives the distribution of first authors by region. During the past few years the fraction of papers from Asia has increased each year. This past year, the fraction of papers is essentially the same. There was a 5\% drop in papers from North America that was accompanied by an increase in papers from Eastern and Western Europe.

As the annual number of submitted manuscripts, regular papers and letters, nears 1000, the journals staff at SPIE (their names are listed on the masthead) must contend with these increases. Besides checking the manuscripts for formatting and completeness and processing them on the PXP server, they must contend with the inevitable glitches. They also keep track of the reviewing process with courteous nudges to the associate editors, the reviewers, and me. They are a pleasure to work with.

Table 6 provides an overview of the activity within the journals office for Optical Engineering. As has been true for years, there were major increases in every aspect of the journal: reviewers, reviews, and revisions.

For the author, the most important performance number is the time it takes to get his or her paper reviewed and, if there is a favorable decision, the time it takes after acceptance for the paper to be published. The transition to Peer X-Press in mid-2004 may have been responsible for a three-week increase in the time it took to review a paper that year. This is a plausible explanation, because, as is shown in Table 7, the average times for both Optical Engineering and $O E$ Letters decreased markedly this past year. I hope this trend will continue.

Once a manuscript has been accepted, the journal staff and editors have less control over the time it takes to publish the paper. Except for 2002 the average production time for Optical Engineering papers is just under 6 months, while OE Letters papers take just 10 weeks. This means that, on average, a paper accepted for OE Letters is published as an Open Access document about 15 weeks after submission. Part of this reduction is due to the new e-First or article-at-a-time publishing, in which the paper is published online as soon as it is ready, rather than, as in traditional publishing, waiting until the issue is printed. With the change to electronic distribution of Optical Engineering this feature will become more useful.

Our research cannot progress unless we publish our work and our work cannot be published until knowledgeable referees have reviewed it. So the peer reviewers are important to us both as authors and readers. I thank all of you who served as reviewers this past year. I trust you will continue to be part of this remarkable combination of our technology and our humanity.

I want to thank the members of the Board of Editors for their contributions toward maintaining these standards. Their names and affiliations are also listed on the masthead. I want to thank Ron Driggers, who has overseen the papers on detectors and infrared technology for many years. His area is now covered by Keith Krapels. Also, I thank Luc Bissonette, Ali Khounsary, Ray Kostuk, and Jiangying Zhou for their efforts of many years. They have been conscientious in rendering decisions and took the time when there were problems or concerns with the papers they were handling to examine them in detail and seek a fair evaluation.

I welcome David Allred, Ralph Tatam, Don Braggins, Greg Sanger, and Edris Mohammed to the Board of Editors. Their willingness to serve is very much appreciated. I thank all of the retiring Associate Editors for their service and the new members of the Board for agreeing to serve. As I have stated in earlier annual reviews, I feel lucky to be able to work with such a great group of people. Thank you all.

Donald C. O'Shea Editor 